\title{
ACTIVE METHODOLOGIES AND AWARE EDUCATION FOR FUTURE SECONDARY SCHOOLS TEACHERS
}

\author{
Consolacion Gil, \& Maria Dolores Gil-Montoya \\ Department of Informatics, University of Almeria (Spain)
}

\begin{abstract}
This experience focus on the use of teamwork techniques such as cooperative learning in conjunction with flipped learning and some computers tools like clickers and digital portfolio as a methodology of learning, reflection, tutoring and evaluation. To promote Aware Education, mindfulness strategies has been used as a way to improve attention and to practice some techniques that can be very useful not only for them but also for their future students when they use them as secondary school teachers.

The experience has been carried out in a subject of the Master Degree in Secondary School Teachers at the University of Almeria (Spain) called Active Methodologies of Teamwork. In this subject, the learning material is based on the different methodologies they are going to learn and practice. Therefore, they are going to learn what cooperative learning is practicing it in small groups. They are going to learn what flipped learning is practicing it and preparing a video about their subject (maths, biology, etc) for their future secondary schools students. They are going to learn what clickers and portfolio are using them and even preparing some quizzes for their future students, and finally, they are going to learn how aware education (mindfulness) can be incorporated to the subject, practicing different meditations during the class as well as formal and informal practices as homework.

The results show that students are more engaged with the learning process and they have developed a greater responsibility not only with their own learning but also with their classmates learning. Also, an increase in the number of students that have passed the subject has been shown. The Mindful Attention Awareness Scale (MAAS) has been carried out at the beginning and at the end of the course to measure the evolution of the students in different items related to mindfulness. These results show that program efficiency has been proven in the 15 items evaluated, with an average increase of $21 \%$.
\end{abstract}

Keywords: Cooperative learning, flipped classroom, gamification, computer tools, aware education.

\section{Introduction}

Teachers of the different educational levels increasingly show different aspects related to low motivation of their students, ease of lossing attention during the class, lack of compression of the theoretical contents, difficulty relating what they are studying with the real world and in general, a reluctant attitude towards study in general (McKeachie, 2006). It is intuited that this is due in large part to the methods used for teaching, mainly the traditional instruction. Thus, in traditional instruction, teachers spend most of the in-class time giving lectures, and students rarely have chances to apply knowledge, or even interact with their peers. Therefore, the need to innovate and use new and disruptive tools that have the ability to capture the attention of students and maintain it during the development of the different activities is more evident than ever (MacManaway, 1970). New instruction systems are based on the use of active methodologies that encourage the active participation of students, making them the core of the entire educational process (Johnson, 1991). Thus, these methodologies stimulated students not only studying the contents of the subjects, but also acquiring skills that are beneficial for their personal and work future (Gil, Baños, Montoya, Alcayde, Gil, Herrada, \& Alvarez, 2018). On the other hand, the consolidation of ICT in Education has meant that, in addition to its use for purely audiovisual purposes (for example, to view transparencies or previously prepared videos), its use as powerful communication tools between teachers and students has allowed breaking the temporal and spatial barriers associated with traditional teaching-learning models, to the point that ICTs have stimulated the consolidation of active methodologies (Gil, Alcayde, Montoya, Baños, Herrada, \& Gil, 2018). Also, the proposals of the so-called "Integral Approach" (Gallifa, 2019) defends the need to connect the cognitive, affective, moral and spiritual dimensions in the teaching-learning processes, based on an active teaching methodology that promotes the (self) awareness of the participants. 
The aim of this work is to analyse a practical experience carried out in a subject of a Master Degree in Secondary School Teachers, in which, future secondary school teachers are trained in different active methodologies. This experience is designed based on previous experiences in learning contexts that make use of active methodologies, such as cooperative learning (Gil, Montoya, Herrada, Baños, Montoya, \& Manzano, 2011) and flipped classroom (Gil et al., 2018). This study aims to show how disruptive and innovative active methodologies, together with ICTs (Information and Communication Technologies) and aware education (García, Gil, Gil, Pulido, Iniesta, \& Aguila, 2019) promote an integral education with a more meaningful and long-term learning. Finally, values, competencies and mainly, a more positive attitude towards learning and life in general, have also been developed.

\section{Design and methods}

The methodology is based on learning the subject using the same methodologies they have to learn. That is, learning cooperative working methodologies by working cooperatively, using the puzzle technique (Johnson, 1991), research groups (Johnson, 1991), gamification through team tournaments (Burke, 2014) and problem based learning for the final project (McKeachie, 2006). Flipped classroom has been used to learn the theoretical knowledge. At the beginning of the next face-to-face session, clickers have been used to know if the students have watched the videos. For this purpose, a tool called ZquizUALbot (Gil et al., 2018) developed by our research group and based on the telegram message application, has been used. Clickers have also been used to evaluate groups after performing some activities. The digital group portfolio has been used to make visible the activities carried out by each group, their reflections, group regulations (Gil et al., 2018) and the self-evaluation and co-evaluation within each group. Different rubrics have also been used for the evaluation of transversal competences (teamwork and oral communication). Each group has presented orally its final project and the rest of the groups have evaluated them (co-evaluation) using the corresponding rubric.

Also, as part of an "aware education project" (García et al., 2019) where this subject is included, a 6-week mindfulness program has been implemented. It includes short meditations in class (five minutes) and formal and informal mindfulness activities for practicing outside the classroom. The following practices have been carried out: 1) Formal mindfulness: meditative practices of attention to breathing, attention to the body and attention to thoughts, 2) Informal mindfulness: practices to bring attention to any activity of daily life, paying attention to breathing and body sensations, 3) Emotional development and self-inquiry: practices to recognize automatic and reactive patterns. For example practicing "active listening" when they are working in groups or "observing mobile phone dependence", counting and being aware of the number of times they need to look at their mobile phone (including social network, message applications, etc).

\section{Discussion and results}

This experience has been implemented with approximately 65 students. All students have been assigned to a cooperative group and have satisfactorily developed all activities (in-class and out of-class). The results have been evaluated through different indicators. The first indicator has been the number of students who have passed the subject, 99\% in 2019-2020 academic year, compared to $97 \%$ of the previously academic years (Gil et al., 2018). Another indicator is a specific quiz with different items and questions about the methodologies of the subject (Gil et al., 2018). The students have rated very positively the use of different active methodologies of teamwork such as cooperative learning, in addition to flipped classroom and gamification. They have also positively assessed the use of computer tools such as e-portfolio to improve teamwork, reflection and self-evaluation, and using clickers to know the degree of monitoring of flipped classroom for the main concepts of the subject.

Figure 1. Average results for the MAAS test (pre and post) for the 15 items.

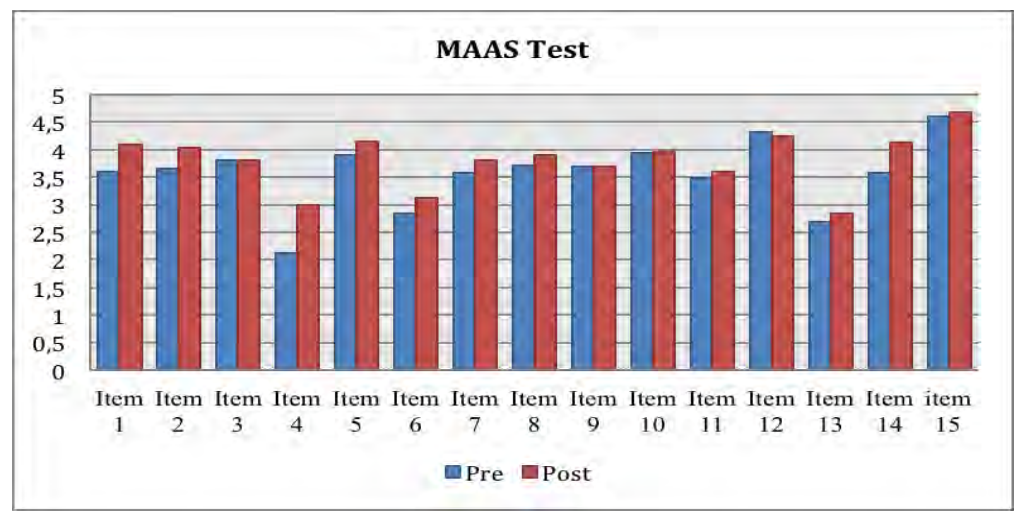


The last analysed indicator during this course is related to mindfulness experience All students who have attended classes have completed formal mindfulness practices. Mindfulness practices outside the classroom have not been mandatory, but more than half of the students have completed them. The Mindful Attention Awareness Scale (MAAS) (Brown, \& Ryan, 2003) has been used at the beginning and at the end of the course to measure the evolution of the students in different issues (items) related to mindfulness. It is a scale that evaluates and records, in a global way, the ability of an individual to be aware of the experience of the present moment in everyday life. It consists of 15 items that are scored according to a Likert scale with a range between 1 (almost always) to 6 (almost never). The final result is obtained from the arithmetic average of the total items. Figure 1 shows these results for 33 students who have completed the MAAS test. Lower scores show lower levels of Mindfulness (related to high levels of stress or anxiety) and the highest show high levels of mindfulness. An increase in the average values of mindfulness is observed in 12 of the 15 issues, with an average increase of $21 \%$.

\section{Conclusions}

It has been shown how this integration between cooperative and flipped learning, gamification and Mindfulness can revolutionize the way the students learn, by putting the student in the core of the learning process. This integral aware educational model can be applied at any level, including primary, secondary and university levels. It has been observed states of well-being, creativity and mental calmness that promote more creative, motivating and meaningful learning both in terms of knowledge, skills, competences and especially values such as empathy, tolerance, compassion and kindness. At the same time, student are given tools to handle stressful situations, complicated emotional situations, both for themselves and so that they can offer them to their future secondary school students. The results obtained in this work make evident the need to apply mindfulness programs within the educational context to improve the well-being states of the students, which also directly influences their academic performance. The results of the MAAS test applied before and after the program support these conclusions. There has also been a significant change in the students involved in the full program, improving the way they interact with peers, facing problems, etc. We conclude with an invitation to those educators with some meditation experience: please find ways to share this gift with your students. And for those educators who are not familiar with any mindfulness practice, we deeply recommend to explore it as an option for their own well-being and growth, as well as for the growth and well-being of their students.

\section{Acknowledgements}

This work has been supported by project 19_20_1_20C Connecting with our Students: How to Promote a more Conscious Teaching / Learning Process of the University of Almería.

\section{References}

Brown, K. \& Ryan, R. (2003). The Benefits of Being Present: and Its Role in Psychological Well-Being. J Pers Soc Psychol. 84. 822-848.

Burke, B. (2014). GAMIFY: How Gamification Motivates People to do Extraordinary Things. EUA: Gartner, Inc.

Gallifa, J. (2019). Integral Thinking and its application to Integral Education. Journal of International Education and Practice, 2(1).15-27.

García, E., Gil, C., Gil, M.D., Pulido, R.A., Iniesta, M.A., Águila, C. (2019). Connecting with our students: how to promote a more conscious teaching/learning process. Edulearn 2019 Proceedings. 4468-4472. ISBN: 978-84-09-12031-4.

Gil, C., Alcayde, A., Montoya, F.G., Baños, R., Herrada, R.I. \& Gil, M.D. (2018). Implementation and analysis of a new tool for clickers. Edulearn 2018 Proceedings. 7359-7367.

Gil, C., Baños, R., Montoya, F.G., Alcayde, A., Gil, M.D., Herrada, R.I. \& Alvarez, J.A. (2018) Cooperative learning and flipped classroom with e-portfolio and clickers tools. Edulearn 2018 Proceedings. 7311-7319. ISBN: 978-84-09-02709-5.

Gil, C., Montoya, M. G., Herrada, R. I., Baños, R., Montoya, F. G. \& Manzano, F. (2011). Cooperative learning and electronic group portfolio: tutoring tools, development of competences and assessment. International Journal of Learning Technology 6(1). 46-61.

Johnson, D. W., R. Johnson \& K. Smith. (1991). Active Learning: Cooperation in the College Classroom, Edina, Minnesota, Interaction Book Company.

MacManaway, I. (1970). Teaching methods in highereducation - innovation and research. Universities. Quarterly 24, 321-329.

McKeachie, W. J., \& Svinicki, M. (2006). McKeachie's teaching tips: Strategies, research, and theory for college and university teachers (12th ed.). Boston: Houghton-Mifflin. 